\title{
OPTIMIZATION AND SIMULATION OF REMANUFACTURING PRODUCTION SCHEDULING UNDER UNCERTAINTIES
}

\author{
$\mathrm{He}, \mathrm{P}$. \\ School of Management, Wuhan Institute of Technology, Wuhan 430205, China \\ E-Mail: heping366@126.com
}

\begin{abstract}
This paper aims to develop a desirable optimization method for the remanufacturing production scheduling under uncertainties. For this purpose, a quality evaluation standard was proposed in light of the two uncertainties, i.e. randomness and ambiguity, of remanufacturing job scheduling. Inspired by the rough set theory and multi-objective approximation sorting algorithm, this evaluation standard can eliminate the redundant information in quality evaluation. On this basis, a remanufacturing production scheduling model was constructed under uncertainties, and solved by a hybrid algorithm developed from the double algorithm, backpropagation (BP) neural network and the genetic algorithm (GA). Simulation results show that the proposed algorithm excels in convergence, and its solution can lead to the minimal scheduling cost and makespan. This algorithm can effectively optimize the scheduling problem of remanufacturing production and processing. The research findings shed new light on the rapid evaluation of recycled resource quality and the optimal scheduling of remanufacturing production.

(Received, processed and accepted by the Chinese Representative Office.)
\end{abstract}

Key Words: Uncertainties, Remanufacturing, Production Scheduling, Optimization, Simulation

\section{INTRODUCTION}

The rapid consumption of energy and resources has led to increasingly severe environmental pollution around the world. Against this backdrop, the circular economy based on "resource recovery-remanufacturing" stands out as an important method for resource saving and sustainable development [1,2]. As the most mature remanufacturing industry, the automotiverelated field relies on the production processes of resource recovery, material screening, reprocessing, assembly, etc. [3, 4].

The production and scheduling of remanufacturing involves many uncertainties. As shown in Fig. 1, these uncertainties occur in such processes as recycling, disassembly, reprocessing and assembly [5-8]. The conventional job-shop scheduling plans no longer apply to remanufacturing production, owing to the differences in manufacturing objects, production processes, production controls and production schedules $[9,10]$.

Much research has been done on the optimization and simulation of remanufacturing shop scheduling. For example, some researchers analysed the impacts of the quality of recycled products (wear, bending, rusting, etc.) on the cost, processing efficiency, and production scheduling during remanufacturing [11-13]. Grguraš and Kramar established a classification standard for recycled resources and introduced it to the optimization of remanufacturing production scheduling [14]. Pan and Wang simplified the remanufacturing process into a flexible job-shop scheduling problem (FJSP) [15]. Considering the effect of recycled product disassembly on remanufacturing production scheduling, Rahman et al. and Ratnaweera et al. put forward an optimal scheduling plan for the minimal makespan and processing cost. They examined the different impacts of in recycled product parameters on production scheduling in remanufacturing shops $[16,17]$. 


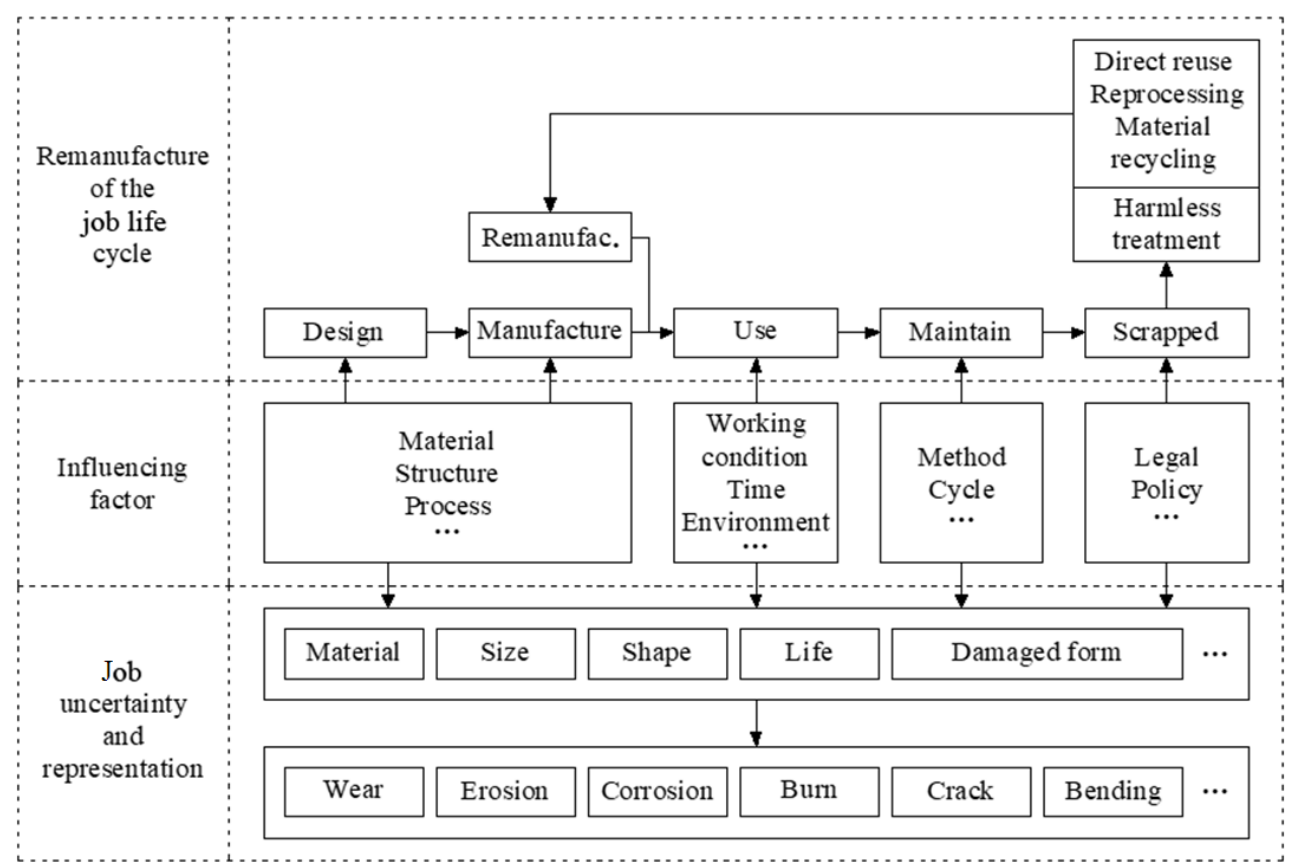

Figure 1: Uncertainties in remanufacturing production.

Meanwhile, some researchers have improved the traditional optimization methods for production scheduling, such as queuing network, radio frequency identification (RFID), intelligent optimization algorithm and information sharing method, and relied on the improved methods to optimize the scheduling of remanufacturing shops, considering the features of remanufacturing and processing [18-20].

To sum up, the above studies either consider a single uncertainty only or discuss the concentrated uncertainties independently. There is no further study on the superposed influence of multiple uncertainties over remanufacturing production decision-making and production scheduling [21-26]. Besides, few reports have been released to illustrate the uncertainties in the actual production of remanufacturing shops or centralized decisionmaking of production plan and scheduling [27].

To solve the above defects, this paper constructs a remanufacturing production scheduling model under uncertainties, and combines the double fuzzy algorithm [28], backpropagation (BP) neural network and genetic algorithm (GA) into a hybrid algorithm to solve the constructed model. The research findings shed new light on the rapid evaluation of recycled resource quality and the optimal scheduling of remanufacturing production.

\section{EVALUATION OF REMANUFACTURED WORKPIECE QUALITY}

In this paper, the parts in automobile engine are taken as the objects for quality evaluation of recycled products. The quality of recycled automobile engines differs greatly with such factors as the driving life, the maintenance condition and the external environment. According to the relevant statistics, the crankshaft in the engine is prone to wear, bending, fatigue and burning during the working process. The following parameters were adopted to classify and evaluate the crankshaft quality: wear (spindle $A_{1}$, connecting $\operatorname{rod} A_{2}$ ), spindle roundness $A_{3}$, cylindricity $A_{4}$, bending degree $A_{5}$, twisting degree $A_{6}$, shaft spacing $A_{7}$, roughness $A_{8}$, crack $A_{9}$ and burning degree $A_{10}$. Table I shows the evaluation and grading standard involving these ten parameters. In the table, the ten parameters are divided into four levels. Among them, level 1 means the crankshaft is little worn and can meet the technical requirements after proper polishing and cleaning; level 2 means the crankshaft has some minor defects and can be used after repair; level 3 means the crankshaft has relatively large defects and cannot be 
used without special secondary treatment; level 4 means the crankshaft has been severely damaged and should be recycled.

Table I: Quality evaluation and grading standard for engine crankshaft.

\begin{tabular}{|c|cccccccccc|}
\hline Level & $A_{1}$ & $A_{2}$ & $A_{3}$ & $A_{4}$ & $A_{5}$ & $A_{6}$ & $A_{7}$ & $A_{8}$ & $A_{9}$ & $A_{10}$ \\
\hline 1 & $0-0.04$ & $0-0.04$ & $0-0.05$ & $0-0.05$ & $0-0.17$ & $0-0.12$ & $0.08-0.26$ & $0.2-0.5$ & no & no \\
2 & $0.04-0.76$ & $0.04-0.76$ & $0.05-0.09$ & $0.05-0.09$ & $0.17-0.32$ & $0.12-0.22$ & $0.26-0.52$ & $0.5-0.7$ & slight & slight \\
3 & $0.76-1.51$ & $0.76-1.51$ & $0.09-0.13$ & $0.09-0.13$ & $0.32-0.52$ & $0.22-0.32$ & $0.52-1.02$ & $0.7-0.9$ & medium medium \\
4 & $1.51-3.0$ & $1.51-3.0$ & $0.13-0.20$ & $0.13-0.2$ & $0.52-1.2$ & $0.32-0.5$ & $1.02-3.0$ & $0.9-1.0$ & severe & severe \\
\hline
\end{tabular}

For real-time evaluation and processing of the recycled crankshaft, the parameters in Table I were discretized as follows:

$$
\operatorname{sgf}\left(p_{k}, D\right)=\frac{\left|\operatorname{POS}_{C}(D)\right|-\left|\operatorname{POS}_{C-\left\{p_{k}\right\}}(D)\right|}{|U|}
$$

where $\operatorname{sgf}\left(P_{k}, D\right)$ is the importance of each evaluation parameter. The value of $\operatorname{sgf}\left(P_{k}, D\right)$ is positively correlated with the importance of the corresponding parameter. The weight of each parameter can be express as:

$$
w\left(p_{k}\right)=\frac{s g f\left(p_{k}\right)}{\sum_{p_{k} \in C} s g f\left(p_{k}\right)}
$$

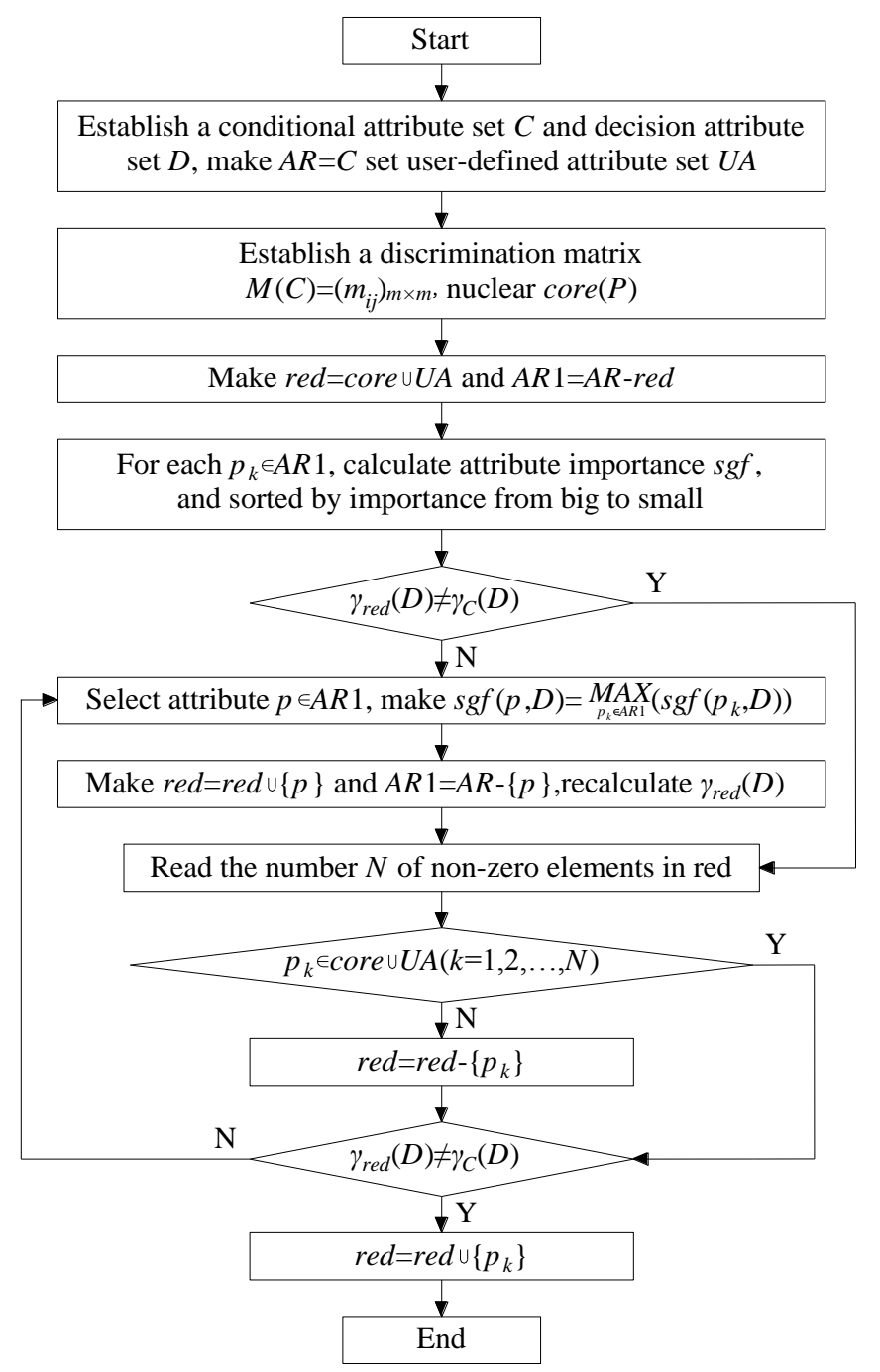

Figure 2: Quality evaluation of engine crankshaft. 
The quality evaluation of engine crankshaft consists of the steps is as shown in Fig. 2 above.

\section{REMANUFACTURING PRODUCTION SCHEDULING MODEL UNDER UNCERTAINTIES AND ITS SOLUTION}

\subsection{Model description}

As shown in Fig. 3, the recycling and remanufacturing of the crankshaft consists of engine disassembly, classification by the established standard, secondary processing and utilization.

In light of the operation process, it is assumed that the scheduling of engine disassembly and crankshaft rework shop involves $m$ machines and $n$ types of jobs, and that the scheduling optimization satisfies the following hypothesis:

(a) Each job corresponds to a set of optimal machines; once selected from the set, a machine can only repair this job at one time.

(b) The job can only be repaired and reworked by the selected machine at one time.

(c) The job can be processed at the initial time, and the makespan covers the time spent in the transport, pre-processing and waiting in the shop.

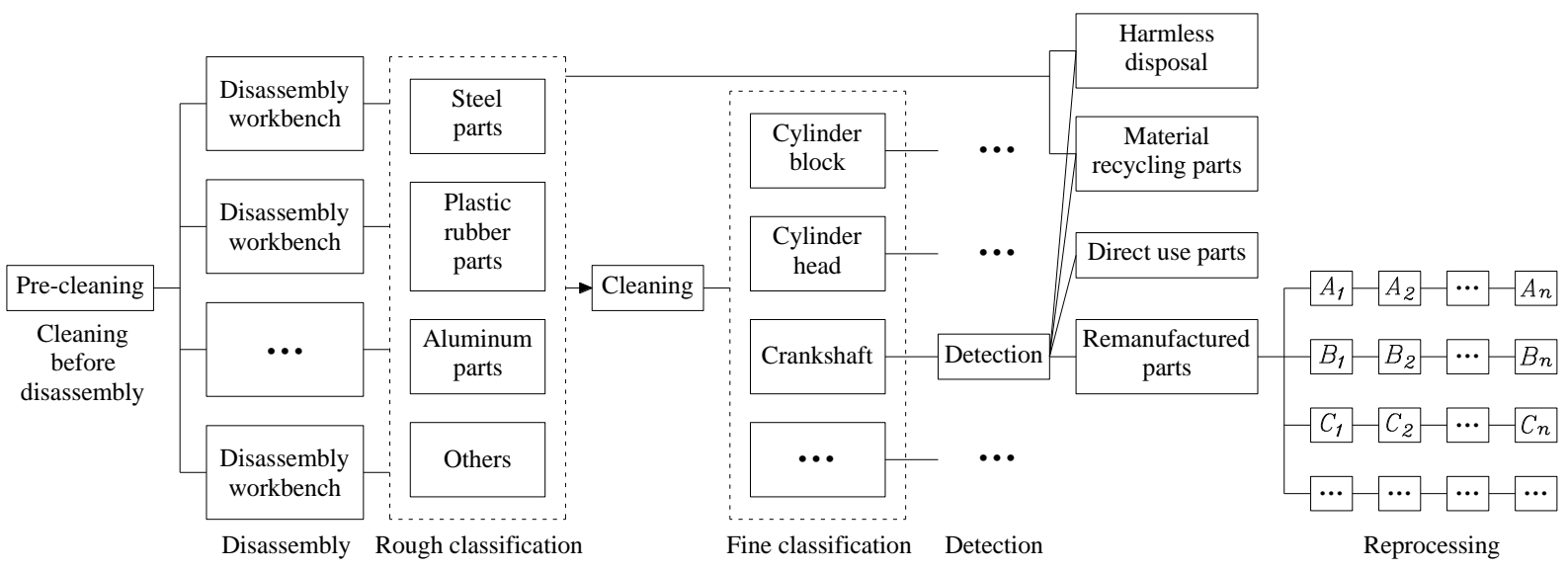

Figure 3: Recycling and remanufacturing of the crankshaft.

The remanufacturing production scheduling model was designed after fully considering two uncertainties, namely, the randomness and ambiguity of shop scheduling in the remanufacturing industry. Meanwhile, the optimal machine and optimal processing sequence were determined for each job at a reasonable level of confidence. The optimization objective function of the model can be expressed as:

$$
\begin{gathered}
\min C=\sum_{i=1}^{N} \sum_{j=1}^{N_{i}} \sum_{k=1}^{M_{i j}} M H C_{i k} \cdot R T_{i j k} \cdot \eta_{i j k} \\
\text { s.t. } \quad E T_{i N_{i}} \leq D D_{i} \\
B T_{i(j+1)}-B T_{i j} \geq R T_{i j k} \\
B T_{i j}-B T_{i^{\prime} j^{\prime}} \geq R T_{i^{\prime} j^{\prime} k}
\end{gathered}
$$

where $i, j$ and $k$ are the serial number of jobs, that of processes and that of machines, respectively; $M H C_{i k}$ is the time cost of job processing; $R T_{i j k}$ is the makespan; $E T_{i j}$ is the processing time of product $i$ in process $j$. Eqs. (4) to (6) are the constraints of the objective function.

The double fuzzy variable was introduced to convert the total makespan of the jobs into a triangular discrete fuzzy variable: 


$$
R T_{i j k}(\theta)=\left\{\begin{array}{c}
\left(\eta_{1}^{1}, \eta_{1}^{2}, \eta_{1}^{3}\right), \theta=\theta_{1} \\
\left(\eta_{2}^{1}, \eta_{2}^{2}, \eta_{2}^{3}\right), \theta=\theta_{2} \\
\ldots \\
\left(\eta_{r}^{1}, \eta_{r}^{2}, \eta_{r}^{3}\right), \theta=\theta_{r}
\end{array}\right.
$$

where $\eta_{r}{ }^{1}, \eta_{r}{ }^{2}$ and $\eta_{r}{ }^{3}$ are the optimistic value, the most likely value and the pessimistic value of the makespan, respectively. In actual scheduling optimization, the value of $\eta_{r}^{3}$ should be minimized. Thus, the double fuzzy constrained model can be expressed as:

$$
\left\{\begin{array}{l}
\min \bar{f} \\
\text { s.t.Ch }\{f(x, \xi) \leq \bar{f}\}(\gamma) \geq \delta \\
\quad \operatorname{Ch}\left\{g_{i}(x, \xi) \leq 0\right\}\left(\alpha_{i}\right) \geq \beta_{i}, i=1,2, \ldots, p
\end{array}\right.
$$

where $\xi$ is the double fuzzy vector. Substituting Eq. (8) to the original scheduling model, the pessimistic value of the total scheduling cost for job production and processing in the entire shop can be adopted as the objective function:

$$
\left\{\begin{array}{l}
\min \bar{C} \\
\text { s.t. } C h\{C \leq \bar{C}\}(\gamma) \geq \delta
\end{array}\right.
$$

Under the above conditions, Eqs. (4) to (6) can be rewritten as:

$$
\begin{gathered}
C r\left\{\theta \in \Theta \mid \operatorname{Cr}\left\{E T_{i N_{i}}-D D_{i} \leq 0\right\} \geq \beta_{i}\right\} \geq \alpha_{i} \\
\operatorname{Cr}\left\{\theta \in \Theta \mid \operatorname{Cr}\left\{R T_{i j k}-B T_{i(j+1)}+B T_{i j} \leq 0\right\} \geq \beta_{i}^{\prime}\right\} \geq \alpha_{i}^{\prime} \\
\operatorname{Cr}\left\{\theta \in \Theta \mid \operatorname{Cr}\left\{R T_{i^{\prime} j^{\prime} k}-B T_{i j}+B T_{i^{\prime} j^{\prime}}\right\} \geq \beta_{i}^{\prime \prime}\right\} \geq \alpha_{i}^{\prime \prime}
\end{gathered}
$$

\subsection{Model solution}

Since it is difficult to solve the remanufacturing production scheduling model under uncertainties through theoretical analysis, this paper combines the double fuzzy algorithm, BP neural network and the GA into a hybrid model to solve the established optimization model.

First, the raw data for model simulation were generated by double fuzzy algorithm:

(1) Find the upper limit $\beta$ at the maximum confidence level of the objective function according to Eqs. (10) to (12), and have $\theta_{k}$ such that $\operatorname{Pos}\left\{\theta_{k}\right\}>\varepsilon$.

(2) For any $r$, there is:

$$
L(r)=\frac{1}{2}\left[\max _{1 \leq k \leq N}\left\{\operatorname{Pos}\left\{\theta_{k}\right\} \mid f\left(\theta_{k}\right) \leq r\right\}+\min _{1 \leq k \leq N}\left\{1-\operatorname{Pos}\left\{\theta_{k}\right\} \mid f\left(\theta_{k}\right)>r\right\}\right]
$$

Obtain the extreme value $r$ when $L(r)>\alpha$, and estimate the objective function.

(3) Take the raw data obtained by double fuzzy algorithm as the training sample, import them into the BP neural network to determine the following functions:

$$
\begin{gathered}
U_{1}(x)=\min \left\{\bar{C} \mid C h\left\{C_{\max } \leq \bar{C}\right\}(\gamma) \geq \delta\right\} \\
U_{i}(x)=C h\left\{E T_{i j}-D D_{i} \leq 0\right\}\left(\alpha_{i}\right) \geq \beta, i=1,2, \ldots, p
\end{gathered}
$$

The GA was employed to optimize the local optimization and slow convergence of BP neural network. First, the initial weight $w$ was updated through improved crossover and mutation operations, and the error function $E_{k}$ was established. Then, the fitness of each $w$ 
was computed through $E_{k}$. The above steps were repeated until the pre-set number of iterations was reached.

Based on process code

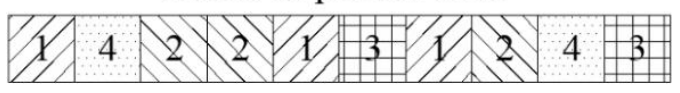

Based onmachine code

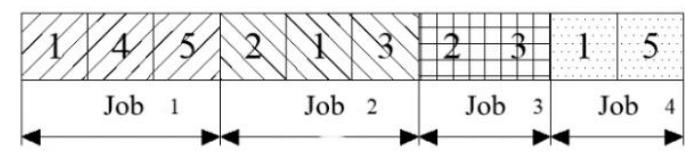

Figure 4: Composite coding.
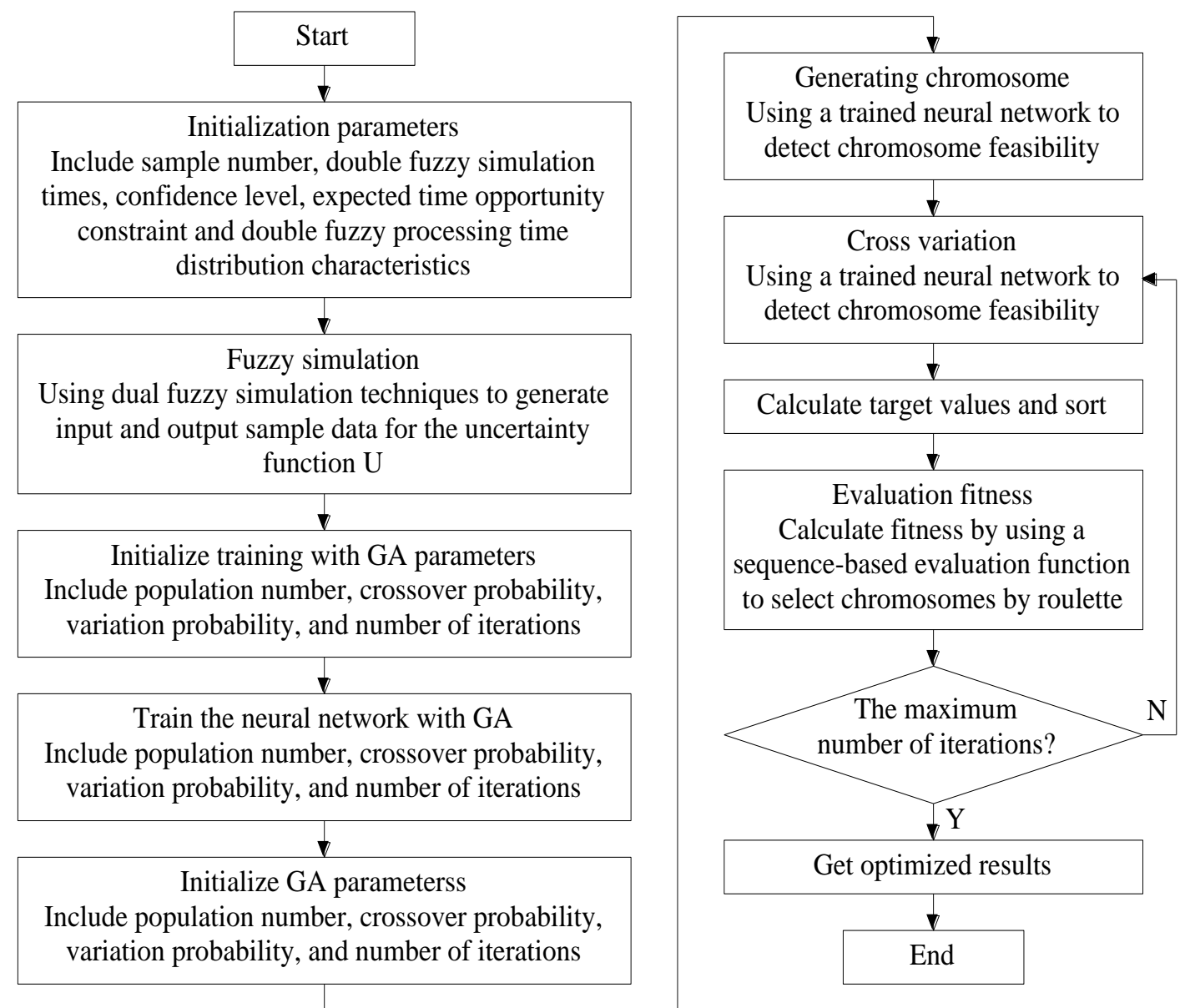

Figure 5: Solving process of the hybrid algorithm.

Through the optimization of the BP neural network by the GA, the author acquired the optimal network structure and parameters. Then, this network structure was embedded in the GA to calculate the target output of the chromosome.

Coding: The chromosomes of the GA were coded through composite coding $(n+m)$, where $n$ is the types of genes in the processing sequence of the entire shop, and $m$ is the types of mapping of jobs to machines. Fig. 4 describes the processing scheduling of 4 jobs on 5 machines.

Initialization: The following parameters of the GA were initialized, including the number of chromosomes, population, crossover operator, genetic operator and iterative threshold.

The calculated values were arranged, and the algorithm was terminated after reaching the pre-set number of iterations. The solving process is illustrated in Fig. 5. 


\section{SIMULATION AND VERIFICATION}

The proposed hybrid algorithm for remanufacturing production scheduling under uncertainties was verified through a case study involving 10 engines to be disassembled. The expected processing scheduling time and the upper and lower boundary confidence levels $(r$ and $\delta$ ) of the internal crankshafts are presented in Fig. 6.

The pre-evaluation results of the 10 engine crankshafts are listed in Table II, where $\mathrm{M}_{1}$ $\mathrm{M}_{3}$ are the machines. The crankshafts were divided into high quality ones and low quality ones according to the evaluation standard in Table I. In Table II, the makespans for $\mathrm{M}_{1}-\mathrm{M}_{3}$ mean the most optimistic, the most likely and the most pessimistic makespans.

Table II: Expected makespan for engine crankshaft processing scheduling.

\begin{tabular}{|c|c|c|c|c|c|}
\hline \multirow{2}{*}{ Job } & \multirow{2}{*}{ Quality level } & \multirow{2}{*}{ Confidence } & \multicolumn{3}{|c|}{ Machine } \\
\cline { 3 - 6 } & & & $\mathrm{M}_{1}$ & $\mathrm{M}_{2}$ & $\mathrm{M}_{3}$ \\
\hline \multirow{2}{*}{$\mathrm{Q}_{1} \mathrm{Q}_{10}$} & Low & 0.14 & $(132,140,148)$ & $(136,142,148)$ & $(126,130,134)$ \\
\cline { 2 - 6 } & High & 0.82 & $(162,177,192)$ & $(158,168,178)$ & $(164,174,184)$ \\
\hline $\mathrm{Q}_{2} \mathrm{Q}_{3} \mathrm{Q}_{4}$ & Low & 0.12 & $(132,137,142)$ & $(135,140,145)$ & $(134,136,138)$ \\
$\mathrm{Q}_{5} \mathrm{Q}_{8} \mathrm{Q}_{9}$ & High & 0.08 & $(157,164,171)$ & $(158,168,178)$ & $(154,165,176)$ \\
\hline \multirow{2}{*}{$\mathrm{Q}_{6} \mathrm{Q}_{7}$} & Low & 0.90 & $(135,138,141)$ & $(137,142,147)$ & $(130,136,142)$ \\
\cline { 2 - 6 } & High & 0.12 & $(156,164,172)$ & $(155,166,177)$ & $(161,171,181)$ \\
\hline
\end{tabular}
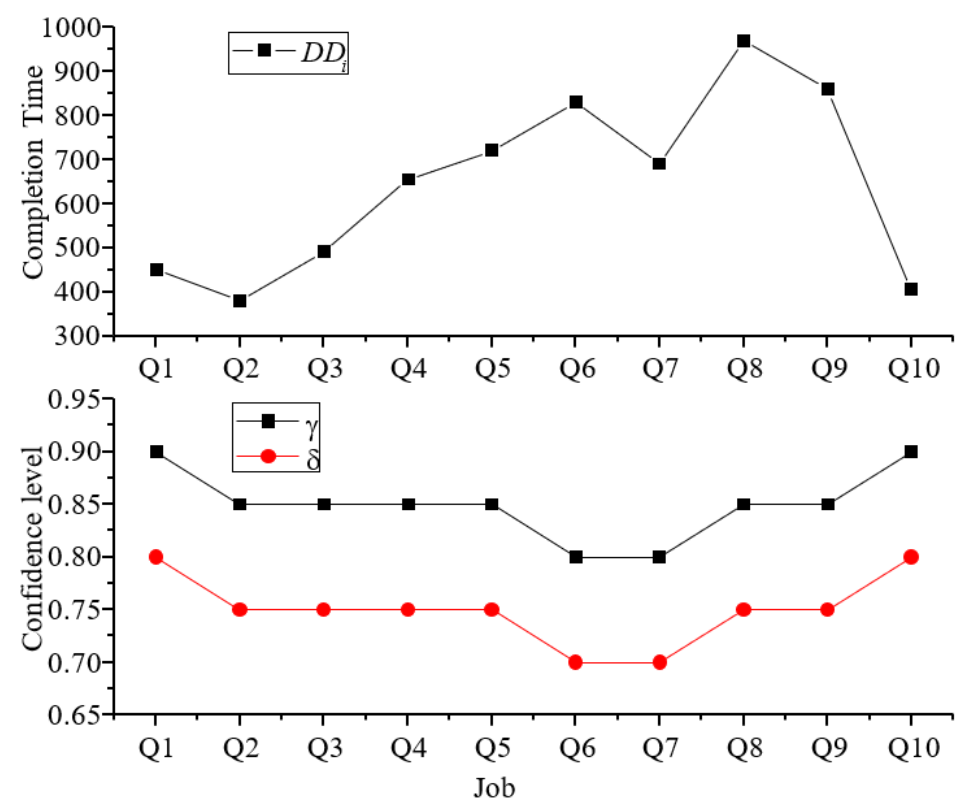

Figure 6: Expected processing scheduling time and the upper and lower boundary confidence levels of crankshafts.

The crossover probability and mutation probability were set to 0.55 and 0.2 , respectively, the total number of iterations to 1,000 , and the initial population size to 50 . The complexities $\mathrm{CD}$ of production scheduling under uncertainties can be expressed as:

$$
C D=O\left(T_{s a} S_{i t} \log n+T_{i t} T_{\text {pop }}+G_{i t}(n p o p+n m \log n)\right)
$$

where $O\left(T_{i t} T_{p o p}\right), O\left(T_{s a} S_{i t} \log n\right)$ and $O(n p o p)$ are the complexities of BP neural network computation, double fuzzy algorithm computation and initialization, respectively. The proposed algorithm is a collection of the above complexities, which are related to the double fuzzy algorithm, BP neural network and the GA.

Table III shows the results of the simulation by the proposed algorithm. It can be seen that the pessimistic value of the scheduling of job production and processing was on the rise with 
the increase of confidence. Because of the huge differences in the processing sequence of each job under different confidence levels, the solution obtained by our algorithms can lead to the minimal total cost and makespan of the production scheduling for jobs under multiple uncertainties, as long as the confidence level remains the same.

According to the convergence curve in Fig. 7, the proposed algorithm converged at the $300^{\text {th }}$ iterations, which demonstrate a good convergence.

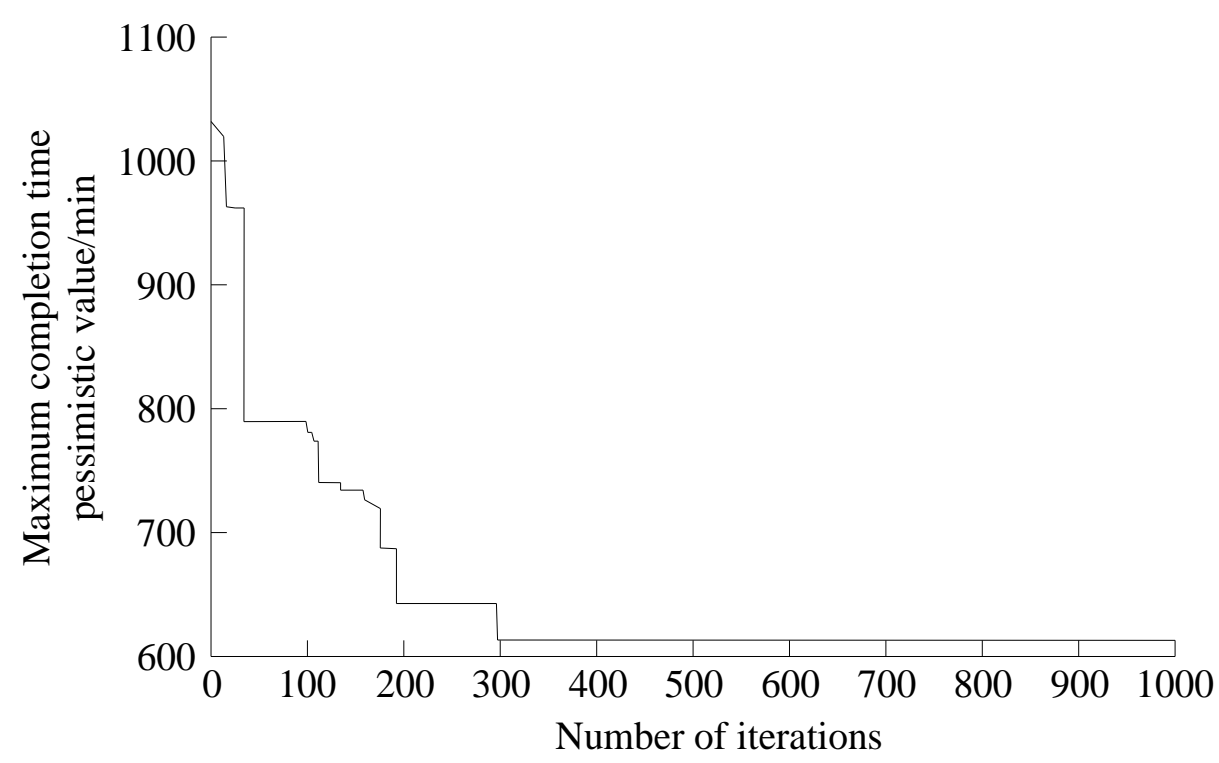

Figure 7: Convergence curve of the optimal solution.

Table III: Simulation results and verification analysis.

\begin{tabular}{|c|c|c|c|}
\hline \multirow{2}{*}{ Confidence } & Completion & \multicolumn{2}{|c|}{ Verification analysis } \\
\cline { 3 - 4 } & cycle $(\bar{f} /$ min $)$ & Original opportunity & Pessimistic value of the completion (cycle/min) \\
\hline 0.7 & 611.2 & 0.90 & 665.6 \\
\hline 0.8 & 641.8 & 0.86 & 697.3 \\
\hline 0.9 & 656.5 & 0.83 & 715.4 \\
\hline
\end{tabular}

\section{CONCLUSIONS}

Considering the multiple uncertainties in remanufacturing production scheduling, this paper creates a remanufacturing production scheduling model under uncertainties, and combines the double algorithm, BP neural network and the GA into a hybrid algorithm to solve the model. The research conclusions are as follows:

(1) The author proposed a quality evaluation method for recycled resources in the remanufacturing industry. Inspired by the rough set theory and multi-objective approximation sorting algorithm, this evaluation standard can eliminate the redundant information in quality evaluation, and serve as a rapid and effective way to evaluate the quality of recycled products.

(2) The proposed model was designed considering two uncertainties, namely, the randomness and ambiguity of shop scheduling in the remanufacturing industry. The raw data for model simulation were generated by the double fuzzy algorithm, and imported to the BP neural network to derive the uncertain function of the model in light of the features of the network. Meanwhile, the GA was employed to solve the local optimum and slow convergence of the BP neural network.

(3) Simulation results show that the proposed algorithm excels in convergence, and its solution can lead to the minimal scheduling cost and makespan. This algorithm can effectively optimize the scheduling problem of remanufacturing production and processing. 


\section{ACKNOWLEDGEMENT}

The research was financially supported by Science Technology Research Foundation of Educational Commission of Hubei Province of China (Grant No. B2018050) and Science Research Foundation of Wuhan Institute of Technology of Hubei Province of China (Grant No. K201777).

\section{REFERENCES}

[1] Guide Jr., V. D. R. (2000). Production planning and control for remanufacturing: industry practice and research needs, Journal of Operations Management, Vol. 18, No. 4, 467-483, doi:10.1016/s0272-6963(00)00034-6

[2] Junior, M. L.; Filho, M. G. (2012). Production planning and control for remanufacturing: literature review and analysis, Production Planning \& Control, Vol. 23, No. 6, 419-435, doi:10.1080/09537287.2011.561815

[3] Chaowanapong, J.; Jongwanich, J.; Ijomah, W. (2017). Factors influencing a firm's decision to conduct remanufacturing: evidence from the Thai automotive parts industry, Production Planning \& Control, Vol. 28, No. 14, 1139-1151, doi:10.1080/09537287.2017.1341652

[4] Zhu, Q.; Tian, Y. (2016). Developing a remanufacturing supply chain management system: a case of a successful truck engine remanufacturer in China, Production Planning \& Control, Vol. 27, No. 9, 708-716, doi:10.1080/09537287.2016.1166282

[5] Huang, M.; Yi, P.; Shi, T.; Guo, L. (2018). A modal interval based method for dynamic decision model considering uncertain quality of used products in remanufacturing, Journal of Intelligent Manufacturing, Vol. 29, No. 4, 925-935, doi:10.1007/s10845-015-1151-4

[6] Ng, M. W.; Waller, S. T. (2012). A dynamic route choice model considering uncertain capacities, Computer-Aided Civil and Infrastructure Engineering, Vol. 27, No. 4, 231-243, doi:10.1111/ j.1467-8667.2011.00724.x

[7] Berce, P.; Pacurar, R.; Balc, N. (2008). Virtual engineering for rapid product development, Proceedings of the WSEAS International Conference on Engineering Mechanics, Structures, and Engineering Geology, 195-200

[8] Li, C.; Liu, F.; Cao, H., Wang, Q. (2009). A stochastic dynamic programming based model for uncertain production planning of re-manufacturing system, International Journal of Production Research, Vol. 47, No. 13, 3657-3668, doi:10.1080/00207540701837029

[9] Petrovic, D.; Duenas, A. (2006). A fuzzy logic based production scheduling/rescheduling in the presence of uncertain disruptions, Fuzzy Sets \& Systems, Vol. 157, No. 16, 2273-2285, doi:10.1016/j.fss.2006.04.009

[10] Chu, Y.; You, F.; Wassick, J. M.; Agarwal, A. (2015). Integrated planning and scheduling under production uncertainties: bi-level model formulation and hybrid solution method, Computers \& Chemical Engineering, Vol. 72, 255-272, doi:10.1016/j.compchemeng.2014.02.023

[11] Lian, Z.; Gu, X.; Jiao, B. (2006). A similar particle swarm optimization algorithm for permutation flowshop scheduling to minimize makespan, Applied Mathematics and Computation, Vol. 175, No. 1, 773-785, doi:10.1016/j.amc.2005.07.042

[12] Nwoji, C. U.; Onah, H. N.; Mama, B. O.; Ike, C. C. (2018). Ritz variational method for bending of rectangular Kirchhoff plate under transverse hydrostatic load distribution, Mathematical Modelling of Engineering Problems, Vol. 5, No. 1, 1-10, doi:10.18280/mmep.050101

[13] Coelho, L. D. S.; Herrera, B. M. (2007). Fuzzy identification based on a chaotic particle swarm optimization approach applied to a nonlinear yo-yo motion system, IEEE Transactions on Industrial Electronics, Vol. 54, No. 6, 3234-3245, doi:10.1109/tie.2007.896500

[14] Grguraš, D.; Kramar, D. (2017). Optimization of hybrid manufacturing for surface quality, material consumption and productivity improvement, Strojniski vestnik - Journal of Mechanical Engineering, Vol. 63, No. 10, 567-576, doi:10.5545/sv-jme.2017.4396

[15] Pan, Q.-K.; Wang, L. (2008). No-idle permutation flow shop scheduling based on a hybrid discrete particle swarm optimization algorithm, International Journal of Advanced Manufacturing Technology, Vol. 39, No. 7-8, 796-807, doi:10.1007/s00170-007-1252-0 
[16] Rahman, M. A.; Anwar, S.; Izadian, A. (2016). Electrochemical model parameter identification of a lithium-ion battery using particle swarm optimization method, Journal of Power Sources, Vol. 307, 86-97, doi:10.1016/j.jpowsour.2015.12.083

[17] Ratnaweera, A.; Halgamuge, S. K.; Watson, H. C. (2004). Self-organizing hierarchical particle swarm optimizer with time-varying acceleration coefficients, IEEE Transactions on Evolutionary Computation, Vol. 8, No. 3, 240-255, doi:10.1109/tevc.2004.826071

[18] Liu, M.; Zhang, X.; Liu, C.; Zhang, M.; Ge, M. (2014). Optimization method of remanufacturing reprocessing shop scheduling under uncertain conditions, Journal of Mechanical Engineering, Vol. 50, No. 10, 206-212

[19] An, Y.-W.; Yan, H.-S. (2013). Solution strategy of integrated optimization of production planning and scheduling in a flexible job-shop, Acta Automatica Sinica, Vol. 39, No. 9, 14761491, doi:10.3724/sp.j.1004.2013.01476

[20] Zhang, X.-D.; Yan, H.-S. (2005). Integrated optimization of production planning and scheduling for a kind of job-shop, International Journal of Advanced Manufacturing Technology, Vol. 26, No. 7-8, 876-886, doi:10.1007/s00170-003-2042-y

[21] Andrew-Munot, M.; Ibrahim, R. N. (2013). Development and analysis of mathematical and simulation models of decision-making tools for remanufacturing, Production Planning \& Control, Vol. 24, No. 12, 1081-1100, doi:10.1080/09537287.2012.654667

[22] Li, C.; Liu, F.; Yi, Q.; Li, C. (2011). A critical chain based uncertain production scheduling method for remanufacturing systems, Journal of Mechanical Engineering, Vol. 47, No. 15, 121126

[23] Rubio, S.; Corominas, A. (2008). Optimal manufacturing-remanufacturing policies in a lean production environment, Computers \& Industrial Engineering, Vol. 55, No. 1, 234-242, doi:10.1016/j.cie.2007.12.009

[24] Zaccone, R.; Sacile, R.; Fossa, M. (2017). Energy modelling and decision support algorithm for the exploitation of biomass resources in industrial districts, International Journal of Heat and Technology, Vol. 35, Special Issue 1, S322-S329, doi:10.18280/ijht.35Sp0144

[25] Chen, H.; Du, J.; Mu, D. (2010). Analysis of the fuzzy programming model of supply chains with uncertain supply and demand, Logistics Technology, Vol. 19, No. 2, 155-158

[26] Yu, G. D. (2016). Modelling for emergency manufacturing resources schedule to unexpected events, International Journal of Simulation Modelling, Vol. 15, No. 2, 313-326, doi:10.2507/IJSIMM15(2)10.348

[27] Xiao, Y. Q.; Wang, L.; Li, Q. (2014). Research on the integration model of process planning and job-shop scheduling, Applied Mechanics \& Materials, Vol. 513-517, 1605-1608, doi:10.4028/ www.scientific.net/amm.513-517.1605

[28] Dai, Y., Zhu, X.; Zhou, H.; Mao, Z.; Wu, W. (2018). Trajectory tracking control for seafloor tracked vehicle by adaptive neural-fuzzy inference system algorithm, International Journal of Computers Communications \& Control, Vol. 13, No. 4, 465-476 